\title{
Instantaneous Power Control Strategy for Voltage Improvement in Power Network Equipped by Wind Generator
}

\author{
Issam Griche ${ }^{1,2^{*}}$, Sabir Messalti ${ }^{1}$, Kamel Saoudi $^{2}$ \\ ${ }^{1}$ Department of Electrical Engineering, Faculty of Technology, University of M'sila, M'sila 28000, Algeria \\ ${ }^{2}$ Department of Electrical Engineering, Faculty of Engineering, University of Bouira, Bouira 10000, Algeria
}

Corresponding Author Email: issam.grich@univ-bouira.dz

https://doi.org/10.18280/jesa.540117

Received: 9 July 2020

Accepted: 26 December 2020

\section{Keywords: \\ power system, wind turbine (WT), instantaneous power control, voltage regulation, sliding mode control (SMC)}

\begin{abstract}
The uncertainty of wind power brings great challenges to large-scale wind power integration. The conventional integration of wind power is difficult to adapt the demand of power grid planning and operation. This paper proposes an instantaneous power control strategy for voltage improvement in power networks using wind turbine improving the dynamical response of power systems performances (voltage and transient stability) after fault. In which the proposed control algorithm based on a new advanced control strategy to control the injected wind power into power system. The efficiency of developed control strategy has been tested using IEEE 9 Bus. Simulation results have showed that the proposed method perform better to preserve optimal performances over wide range of disturbances for both considered scenarios studied short circuit and variable loads.
\end{abstract}

\section{INTRODUCTION}

Wind power generation is growing rapidly in recent years all around the world. However, the intermittent and uncertain characteristics may bring great challenges to the secure and stable operation of the electric power system [1]. Accurate wind power forecasting is playing an increasingly important role in the planning, operation, and even power marquet of the power system [2].

Among them, conventional generating units combined with several renewable generating units to respond to meet the need for electric power to the consumers. If synchronous generators which that experience these devices installed is out of service to allow the system to accommodate the new wind power generation, their damping contribution is obviously lost [3, 4]. The focus of recent research has been on a stability problem during integration in power system [5]. However, very few publications can be found are available in the literature that discusses to solve this problem of stability [5].

Several authors have studied the impact of various wind generators on power system using different tools and softwares. The simulations were performed on very simple grid with three-phase fault occurring near a wind generator [6].

Recently, Hansen et al. [7] have discussed several models using the power system simulation tool DIgSILENT. An excellent overview and literature review of detailed modeling for the turbine and the induction generator have been included $[8,9]$.

Therefore, wind energy converters (WECs) may in the future be able to improve voltage and power flows. Due to variations in the power output from (WECs) due to its nonlinear structure, instability may occur in the system $[10,11]$. Voltage Oriented Control (VOC) equipped with the constant switching frequency (CSF) based on a phase lead compensation are able to improve the network damping by the coordinated control of power network based wind power generation was discussed by the authors $[12,13]$. From the studies, wind turbine equipped with the voltage source converter is applicable to deal with the converter's average voltage vector in control requirements [14].

In the past few years, the direct power control (DPC) has been paid much attention for its simple structure, fast dynamic response under transient conditions. Recently, the (DPC) has been widely used to control the electronics interface in the wind generation systems [15-17].

From the literatures, it shows the coordinated design of Sliding Mode Control (SMC) strategy [18], direct power control (DPC) and space vector modulation (SVM) approach for DC/AC converter [19, 20]. In sum, it is clear from the literature survey that the application of these techniques to solve the problem of voltage regulation. This encourages us to propose a new technique to deal with this problem with integration of wind power generation is addressed to a single machine whereas the less attention is paid for multi machine systems [21].

In this paper, instantaneous wind power control strategy is presented for the purpose of improving the quality of the voltage profile. Moreover, in order to examine the efficiency of the proposed method, many scenarios have been applied to IEEE 9bus test power system to demonstrate the efficiency of the proposed method. The results showed that the voltage regulation based controller can guarantee a good damping characteristic for power system oscillations and manage the instantaneous powers. The simulations are performed using the Matlab-Simulink program.

The main contributions of this work are given by the following points:

- The effectiveness of the voltage and pitch controller to detect the instantaneous power.

- $\quad$ Proposed a new sliding mode controller (SMC) to inject the required power generated by wind farm. 
- The advantages of the proposed control approach have been validated considering the power system in over load and fault disturbances.

The rest of the paper is organized as follows. In Section 2, the power system model is illustrated in which the synchronous generator model and the wind turbine model have been described in details. However, the control strategy of injected wind power based on sliding mode is presented is in Section 3. In section 4 simulation results of the proposed method will be presented and analyzed. In the end, sum comments have been summarized in Section 5 .

\section{POWER SYSTEM MODELING}

Figure 1 shows the IEEE 9bus power system including 3 generators linked together by 6 lines $230 \mathrm{kV}$ lines of different length which the parameters are given by Kundur [22]. It was purposely designed to review low frequency electromechanical oscillations in large interconnected power systems. Regardless of its small size, it mimics very closely the behavior of typical systems in actual operation. Each synchronous generator is equipped with rated power 247.5, 192, 128 MVA respectively. The load is represented as constant impedances. Since the surge impedance loading of a single line is about $125,90,100 \mathrm{MW}$ located in the bus 5, 6 and 8 respectively. To study the efficient of wind turbine, wind farm is connected near the generator 3 , the details are provided by Huda and Živanović [23]

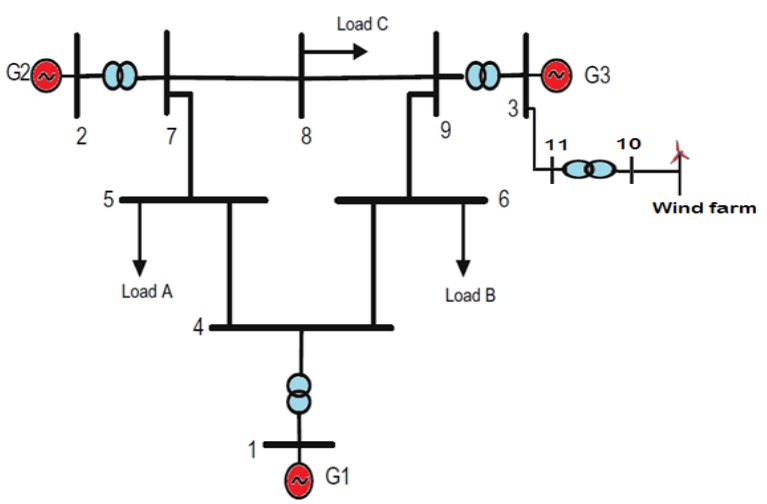

Figure 1. Structure power system under study

\subsection{Synchronous generator model (SGM)}

In this study, the dynamic behavior of machines is described by the following equations. For $\mathrm{i}=1$ to 3 ,

$$
\begin{gathered}
\dot{\delta}_{i}=\left(\omega_{i}-\omega_{b}\right) \\
\dot{\omega}_{i}=\frac{\omega_{b}}{2 H_{i}}\left[P_{m i}-P_{e i}-D_{i}\left(\omega_{i}-\omega_{b}\right)\right] \\
\dot{E}_{q i}^{\prime}=\frac{1}{T_{d 0 i}^{\prime}}\left[V_{e x i}-E_{q i}^{\prime}+\left(x_{d i}-x_{d i}^{\prime}\right) I_{d i}^{\prime}\right] \\
\dot{E}_{d i}^{\prime}=\frac{1}{T_{q 0 i}^{\prime}}\left[-E_{q i}^{\prime}-\left(x_{q i}-x_{q i}^{\prime}\right) I_{q i}^{\prime}\right]
\end{gathered}
$$

$$
\begin{gathered}
\frac{d V_{e x}}{d t}=\frac{1}{T_{E}}\left[V_{R}-\left(S_{E}+K_{E}\right) V_{e x}\right] \\
\frac{d V_{1}}{d t}=\frac{1}{T_{R}}\left(V_{r e f}-V_{t}-V_{1}\right) \\
\frac{d V_{2}}{d t}=\frac{1}{T_{F}}\left(K_{F} \frac{d V_{e x}}{d t}-V_{2}\right)
\end{gathered}
$$

where, $K_{A}, K_{E}, K_{F}$ are the gains, $T_{A}, T_{E}, T_{F}$ are system time constants, $V_{1}, V_{2}, V_{e x}, V_{R}$, are the AVR state variables and $V_{r e f}$ is the terminal voltage reference setting.

\subsection{Wind turbine model}

The Doubly Fed Induction Generator (DFIG) can be operated at variable speed using power converters and can generate electric power over a wide range of wind speeds. The controller objectives of the wind generation system can be arranged in the energy capture, manage power flows and injected power quality. These objectives are achieved by the wind generation system control strategies. Figure 2 describes the topology of the wind generation system based on DFIG.

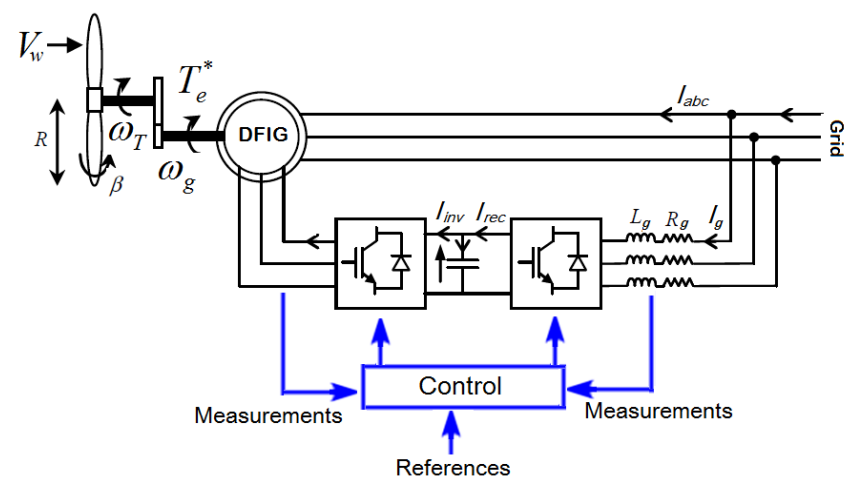

Figure 2. Topology wind generation system

The mechanical power $\mathrm{P}_{\mathrm{T}}$ captured from a wind turbine is given by [11]:

$$
\begin{gathered}
P_{T}=\frac{1}{2} \rho \pi R^{2} C_{p}(\lambda, \beta) V_{w} \\
\lambda=\frac{R \omega_{T}}{V_{w}}
\end{gathered}
$$

The power coefficient is written by the following equation:

$$
\begin{gathered}
C_{p}(\lambda, \beta)=0.5109\left(\frac{116}{X}-0.4 \beta-5\right) \exp \left(-\frac{21}{X}\right)+116 \lambda \\
X=\frac{1}{\lambda+0.08 \beta}-\frac{0.035}{1+\beta^{3}}
\end{gathered}
$$

For different conditions (wind speed, generator speed), the electrical torque is presented in Figure 3, in which we can 
observe that the wind turbine can generate the maximum mechanical power at only one point for each wind speed (MPPT). The optimum operating is given by:

$$
T_{e}^{*}=K_{m} \omega_{g}^{2}
$$

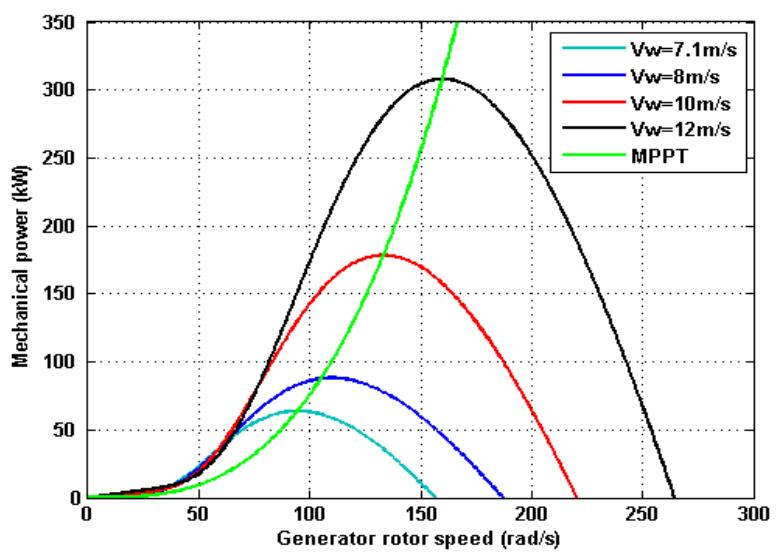

Figure 3. Mechanical characteristics of the WECs for different wind speed

Figure 4 describes the model and proposed pitch control applied to the wind turbine.

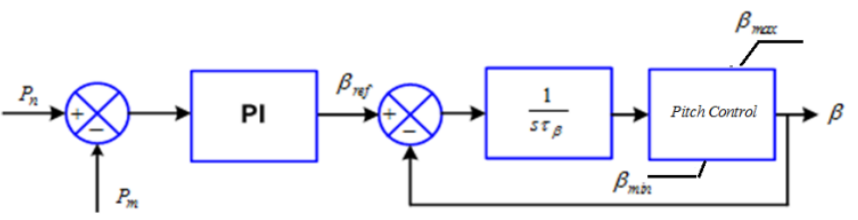

Figure 4. Model of the proposed pitch control

\section{PROPOSED INSTANTANEOUS POWER CONTROL ALGORITHM}

In this section, the sliding mode control (SMC) strategy is proposed. As an improved approximate the sliding surfaces of the proposed controller are set as:

$$
s(t)=\left(\frac{d}{d t}+\lambda\right)^{n-1} e
$$

The calculation steps of the proposed controller are listed as follows:

1. Active and reactive power error:

$$
\begin{aligned}
& s(P)=\left(P_{s-r e f}-P_{s}\right) \\
& s(Q)=\left(Q_{s-r e f}-Q_{s}\right)
\end{aligned}
$$

2. Derivatives of the sliding surfaces:

$$
\begin{aligned}
& \dot{s}(P)=\frac{d s(P)}{d t} \\
& \dot{s}(Q)=\frac{d s(Q)}{d t}
\end{aligned}
$$

$$
\begin{aligned}
& \dot{s}(P)=\left(\dot{P}_{s-r e f}-\dot{P}_{s}\right) \\
& \dot{s}(Q)=\left(\dot{Q}_{s-r e f}-\dot{Q}_{s}\right)
\end{aligned}
$$

3. Active and reactive power equation:

$$
\begin{aligned}
& \dot{s}(P)=\left(\dot{P}_{s-r e f}+\frac{V_{s} M}{L_{s}} \dot{I}_{r q}\right) \\
& \dot{s}(Q)=\left(\dot{Q}_{s-r e f}+\frac{V_{s} M}{L_{r}} \dot{I_{r d}}\right)
\end{aligned}
$$

4. Current expression:

$$
\begin{aligned}
& \dot{I_{r q}}=\frac{1}{L_{r} \sigma}\left(V_{r q}-R_{r} I_{r q}\right) \\
& \dot{I_{r d}}=\frac{1}{L_{r} \sigma}\left(V_{r d}-R_{r} I_{r d}\right)
\end{aligned}
$$

5. Control law design $V_{r d}, V_{r q}$

$$
\begin{aligned}
& V_{r q}=V_{r q}^{e q}+V_{r q}^{n} \\
& V_{r d}=V_{r d}^{e q}+V_{r d}^{n}
\end{aligned}
$$

6. Expression of active and reactive power:

$$
\begin{aligned}
& \dot{s}(P)=\left(\dot{P}_{s-r e f}+\frac{V_{s} M}{L_{r} L_{s} \sigma}\left(\left(V_{r q}^{e q}+V_{r q}^{n}\right)-R_{r} I_{r q}\right)\right) \\
& \dot{s}(Q)=\left(\dot{Q}_{s-r e f}+\frac{V_{s} M}{L_{r} L_{s} \sigma}\left(\left(V_{r d}^{e q}+V_{r d}^{n}\right)-R_{r} I_{r d}\right)\right)
\end{aligned}
$$

7. Permanent regime or steady state

$$
\begin{aligned}
& s(P)=0, \dot{s}(P)=0, V_{r q}^{n}=0 \\
& s(Q)=0, \dot{s}(Q)=0, V_{r d}^{n}=0
\end{aligned}
$$

8. Equivalent control $V_{r q}^{e q}, V_{r d}^{e q}$

$$
\begin{aligned}
& \left(\begin{array}{l}
\left.V_{r q}^{e q}=\dot{P}_{s-r e f} \frac{L_{r} L_{s} \sigma}{V_{s} M}+R_{r} I_{r q}\right) \\
V_{r q}^{n}=K_{V r q} \operatorname{sign}(s(P))
\end{array}\right) \\
& \left(\begin{array}{l}
V_{r d}^{e q}=-\dot{Q}_{s-r e f} \frac{L_{r} L_{s} \sigma}{V_{s} M}+R_{r} I_{r d} \\
V_{r d}^{n}=K_{V r d} \operatorname{sign}(s(Q))
\end{array}\right)
\end{aligned}
$$

9. Quadratic Lyapunov function

$$
W=\frac{1}{2} s^{T} S
$$


10. Stability condition

If $\left\{\begin{array}{l}s(P) \operatorname{sgn}(s(P)) \succ 0 \\ s(Q) \operatorname{sgn}(s(Q)) \succ 0\end{array}\right.$ then $\frac{d W}{d t}=s^{T} \frac{d s}{d t} \prec 0$

11. Elimination of the problem of chattering

$$
\operatorname{sgn}\left(s_{j}\right)=\left\{\begin{array}{llc}
1 & \text { if } & s_{j}>D_{j} \\
\frac{s_{j}}{D_{j}} & \text { if } & \left|s_{j}\right| \leq D_{j} \\
-1 & \text { if } & s_{j}<-D_{j}
\end{array}\right.
$$

To produce the required active and reactive power, sliding mode control is used to generate the appropriate rotor voltage $\left(\mathrm{V}_{\mathrm{dr} \_ \text {ref }}\right.$ and $\left.\mathrm{V}_{\mathrm{qr} \_ \text {ref }}\right)$ as shown in Figure 5.

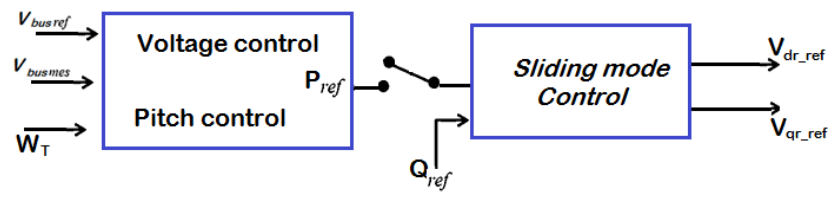

Figure 5. Block diagram of the proposed instantaneous control
Figure 6 present the structure of controller to control the voltage in power system. The input signal of this controller is the value of the voltage bus in the power system which is subject to an anti-windup limiter where $P^{\min }$ and $P^{\max }$ are minimum and maximum of output power respectively

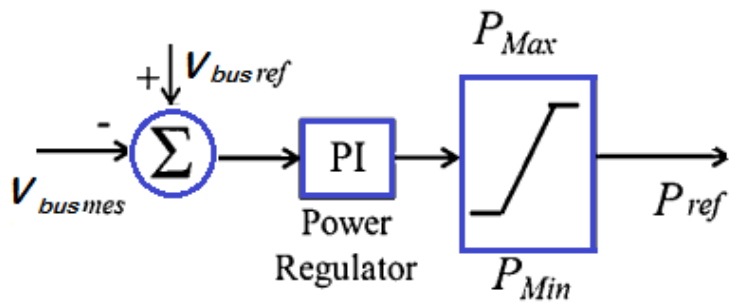

Figure 6. Model of the proposed pitch control

The control strategies of wind turbine based on DFIG is illustrated in Figure 7, in which the configuration of the doubly fed induction generators in wind generation system and the proposed control strategies for the AC/DC/AC conversion structure. This configuration allows to extract the maximum power from the wind at every moment and to inject it to the grid. The generated power is managed by the power electronics. The proposed control strategies aiming to controlling the powers flows and optimized the energy capture from the wind with securely.

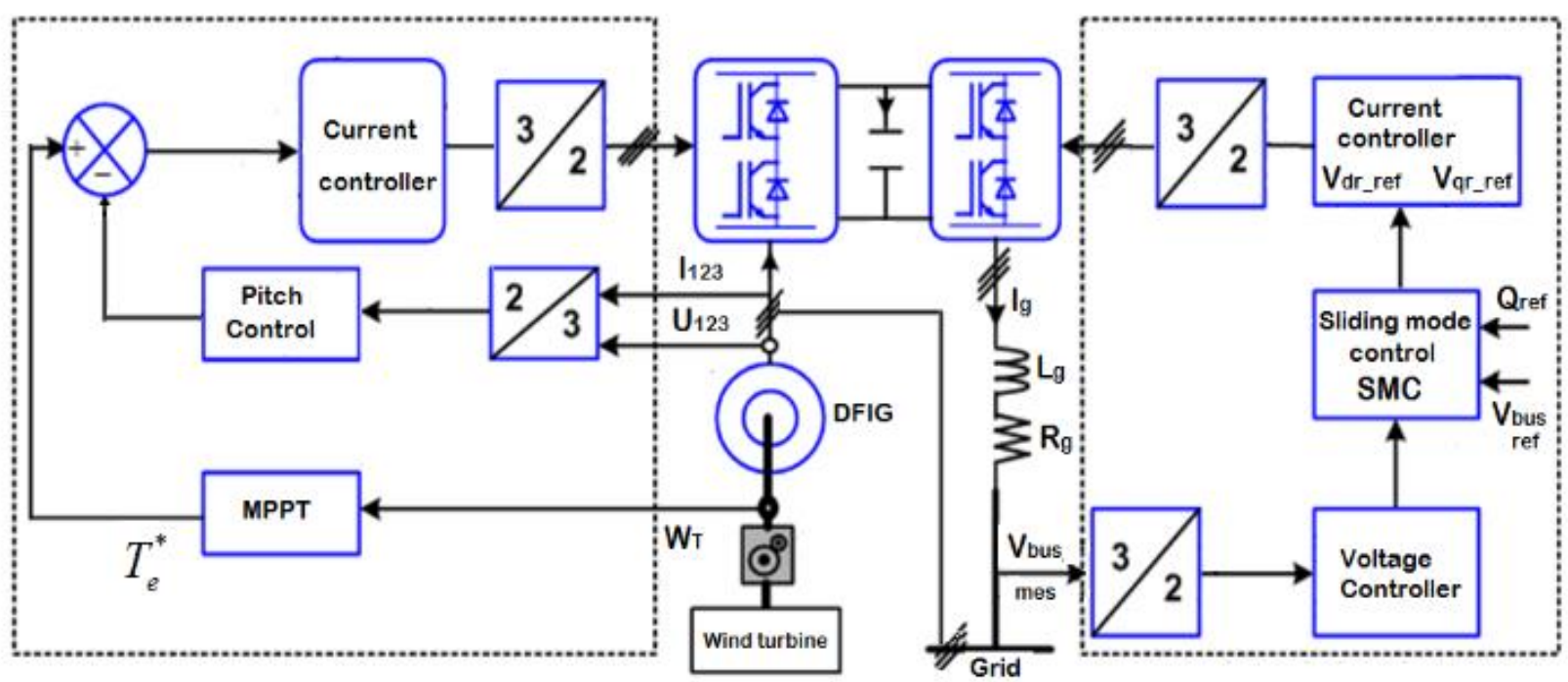

Figure 7. Control strategies structures for wind generation system

\section{SIMULATIONS RESULTS}

To validate the performance of the developed control strategies and to sweep the operating areas operation of the wind generation system, several simulations were carried out.

The performance of the designed controller has been evaluated on IEEE 9bus power system for different scenarios (over load and short circuit), in which both cases will be presented, the first consider power system without wind turbine, the second the power system is equipped by wind turbine control based on prosed sliding mode control.

A 3 machines- 9 bus system is used to evaluate the proposed model. Time domain simulations using Matlab-Simulink environment under PSAT toolbox are performed for over load and a three-phase fault is applied to bus 6 and cleared at 0 and $0.1 \mathrm{sec}$ respectively.

\subsection{Case 1: Without integration of wind farm}

The first simulation, we increased the load connected at bus 6 , in which the load has been changed from 100MW to 130MW. The voltage profile of all buses of the power system is given in Figure 8. The obtained voltage at all buses of the power system has completely affected by the considered over load. Hence, we try to study the impact of wind power injected in section 4.2 . 

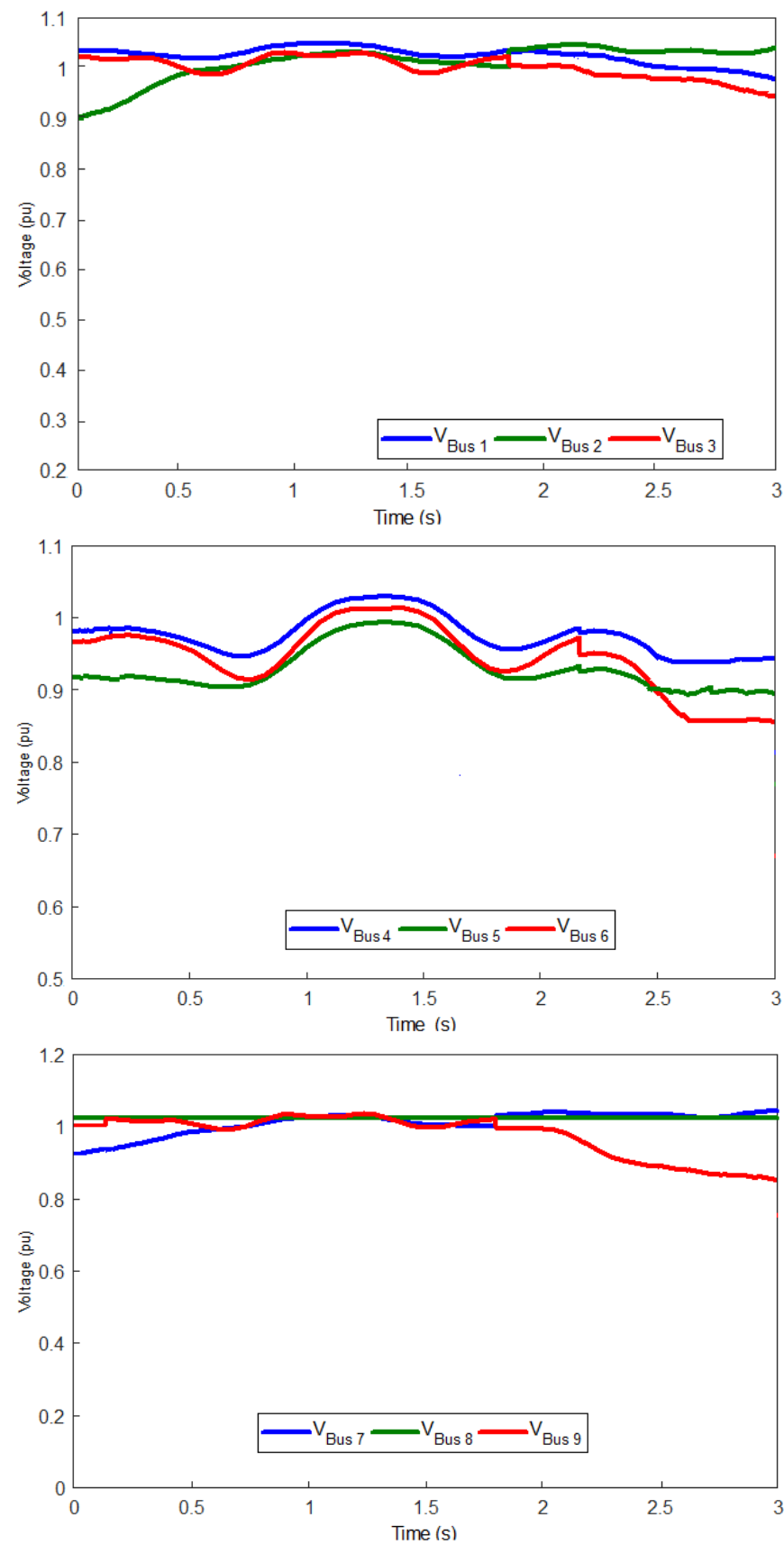

Figure 8. Voltage profile in all buses test system with the over load B at bus 6 without wind power injection

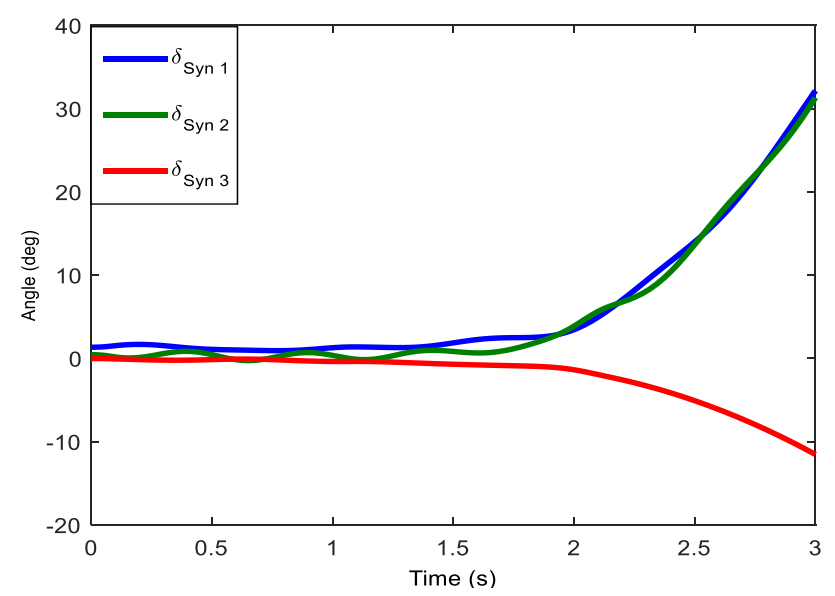

Figure 9. Rotor angle of three generators without wind power injection

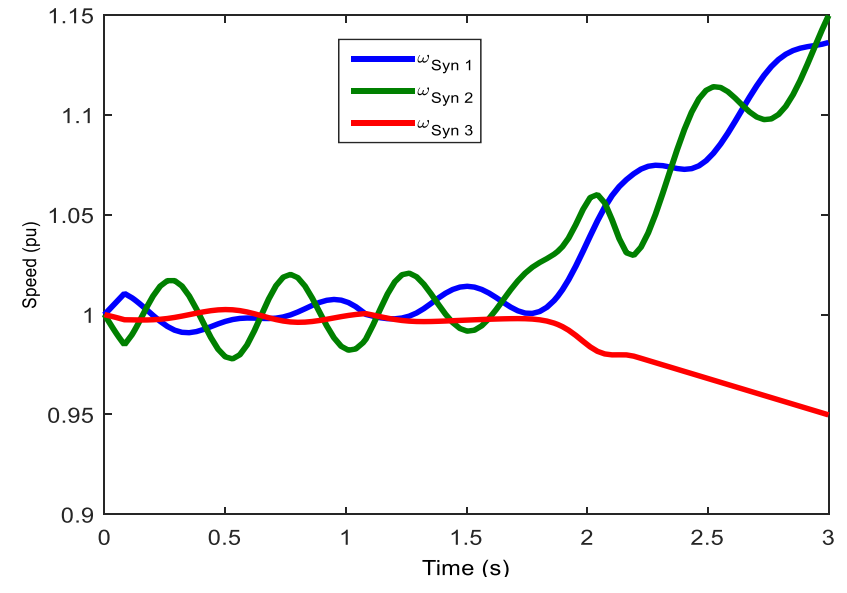

Figure 10. Speed of three generators without wind power injection

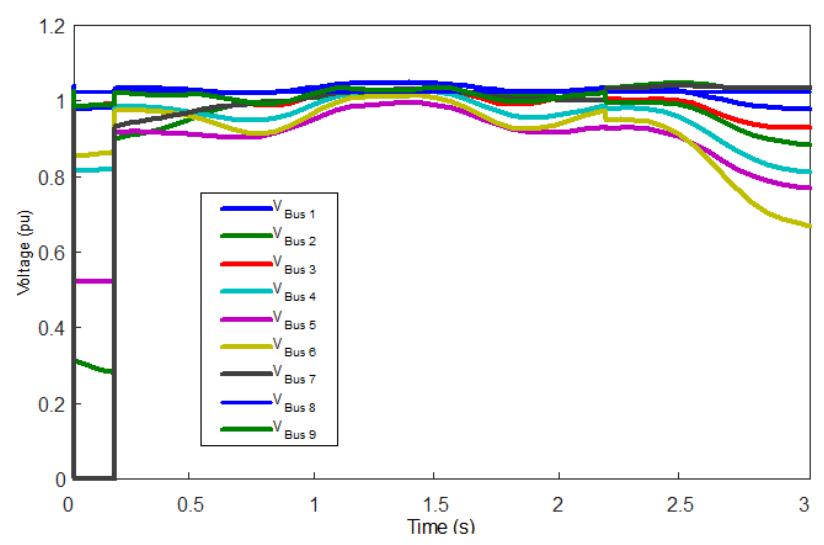

Figure 11. Voltage profile of all buses without wind power injection

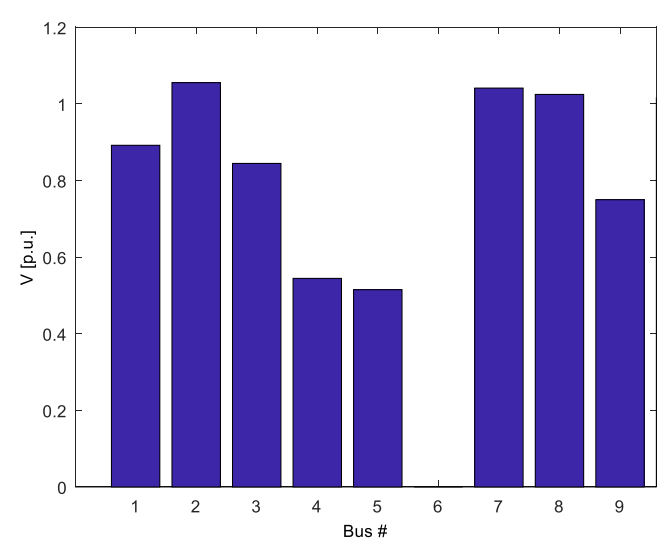

Figure 12. Specters of voltage of all bus without wind power injection

The second case, we have applied the symmetrical three phase short circuit fault on one transmission line at bus 6 . Figure 9, 10, 11 and 12 displays the oscillations for the power system response to this disturbance. It is clear that the power system has lost its performance. As predicted, the voltage profile has a longer value.

\subsection{Case 2: With integration of wind farm}

This scenario, it is assumed that a wind farm occurred near the generator 3 . The one wind turbine parameters are illustrated by Table 1 and Table 2 [13], where the global wind power generated is given by the following equation: 


$$
P_{\text {WindTotal }}=\sum_{i=1}^{n} P_{\text {Wind }}
$$

In our case, the number of wind turbine is 35 which the total power injected is $58.8 \mathrm{MW}$.

Table 1. Induction machine parameters

\begin{tabular}{cc}
\hline Parameters & Values \\
\hline Rated power $(\mathrm{MW})$ & 1.68 \\
Machine rated speed $(\mathrm{tr} / \mathrm{mn})$ & 1515 \\
Number of pole pairs & 2 \\
Stator resistance $(m \Omega)$ & 6.3 \\
Rotor resistance $(m \Omega)$ & 4.8 \\
Stator Inductance $(\mathrm{mH})$ & 11.8 \\
Rotor Inductance $(\mathrm{mH})$ & 11.6 \\
Magnetizing Inductance $(\mathrm{mH})$ & 11.6 \\
Nominal voltage $(\mathrm{V})$ & 690 \\
\hline
\end{tabular}

Table 2. Wind turbine parameters

\begin{tabular}{cc}
\hline Parameters & Values \\
\hline Rated power (MW) & 1.68 \\
Optimal power coefficient & 0.475 \\
Optimal tip speed ratio & 8.1 \\
Turbine radius $(\mathrm{m})$ & 14 \\
Nominal wind speed $(\mathrm{m} / \mathrm{s})$ & 12 \\
Minimum wind speed $(\mathrm{m} / \mathrm{s})$ & 4 \\
Gear box & $1 / 23$ \\
Equivalent Moment of inertia $\left(\mathrm{kg} . \mathrm{m}^{2}\right)$ & 50 \\
\hline
\end{tabular}

The wind speed is given by Figure 13 which is applied to the grid-connected wind turbine. The power coefficient decreases and assumes a constant value relative to degrade the power and return it to its nominal value for wind speed above the nominal value. For a wind speed above to the rated value, we note a stabilization in the power coefficient shown in Figure 14 and 15 . We illustrate the variation of the power coefficient depending on the wind speed which shows the principle of the aerodynamic control for lower wind speed than the value of the rated speed. It shows the performance of the proposed control of the DFIG the control objectives are accomplished given the maximum power coefficient.

Also, in this scenario, another severe disturbance is considered for different loading conditions; that is, a threephase fault is applied at the same above mentioned location in scenario 1 .

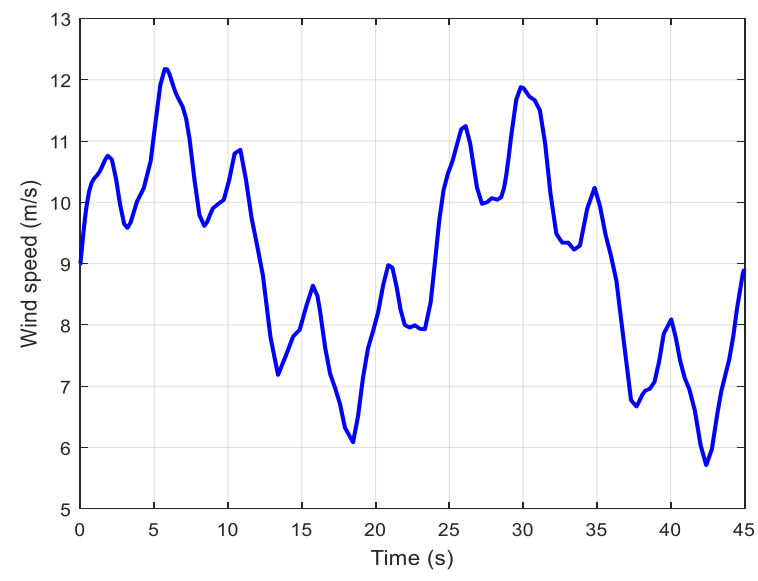

Figure 13. Wind speed

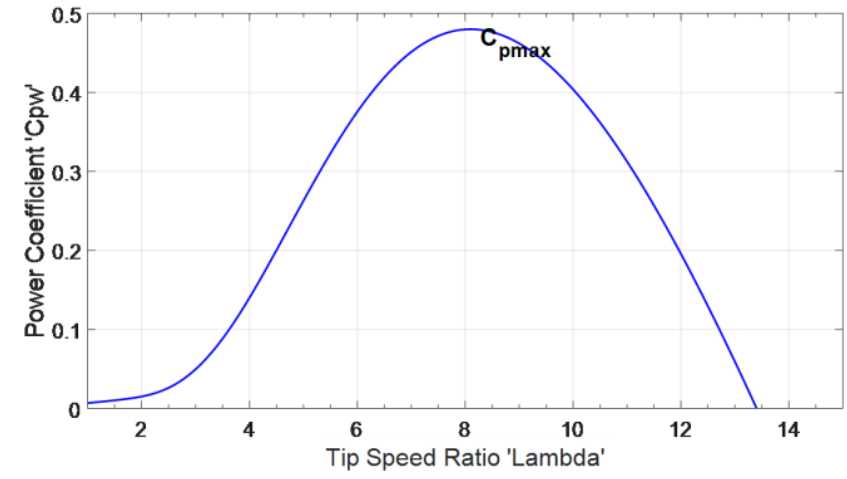

Figure 14. Power coefficient according speed ratio $\lambda$

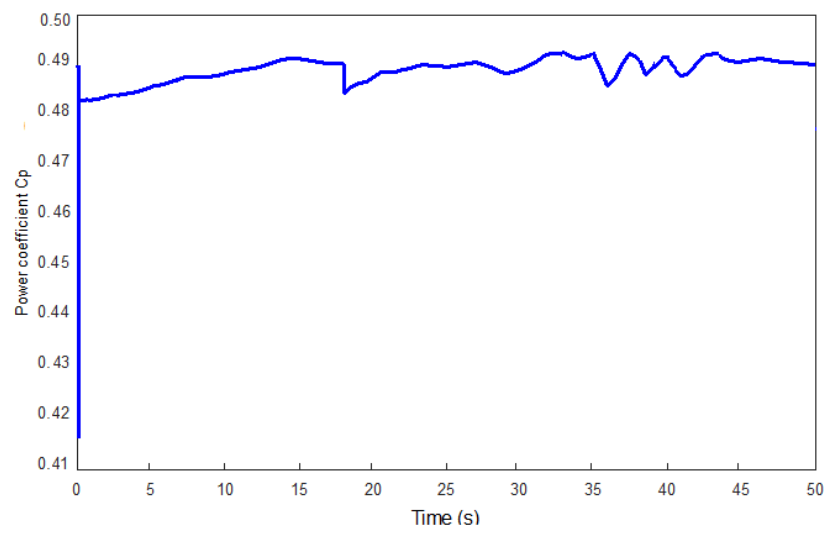

Figure 15. Power coefficient $\mathrm{Cp}$

Figure 16 represents the evolution of mechanical power depending on the wind speed. The production curve includes two parts, one based on a MPPT algorithm for extracting the maximum power from $V_{w \text { min }}=4 \mathrm{~m} / \mathrm{s}$ up to the nominal wind speed $V_{w \max }=12 \mathrm{~m} / \mathrm{s}$ and the other part it shows the response of the pitch control algorithm which limits the mechanical power captured to high wind speed above the rated speed $12 \mathrm{~m} / \mathrm{s}$.

The fault is cleared with line tripping and the original system is restored upon the clearance of the fault. The system response to this disturbance is shown in Figures 17, 18, 19, 20 and 21.

Clearly, the instantaneous power control can suppress all oscillations satisfactorily. The best performance belongs to the proposed controller and has good damping oscillations and improve the voltage regulation.

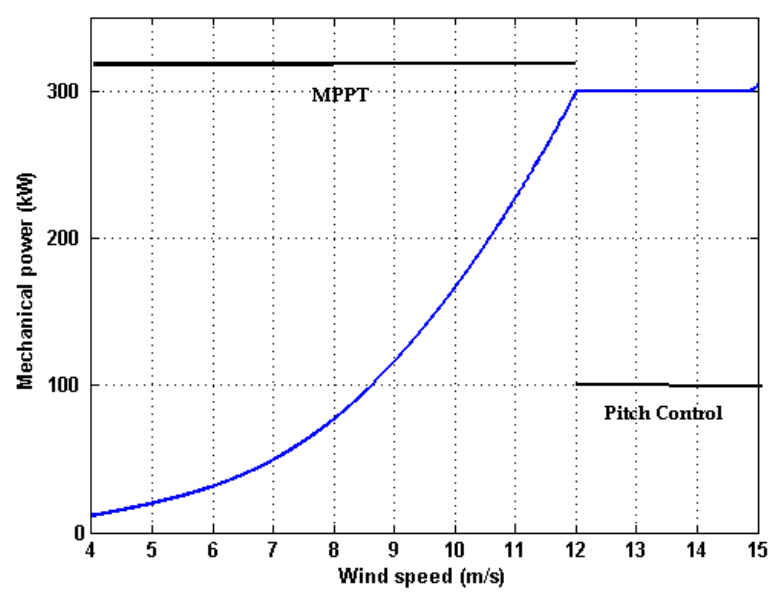

Figure 16. Evolution of the mechanical power versus wind speed for the operating areas of the wind turbine 


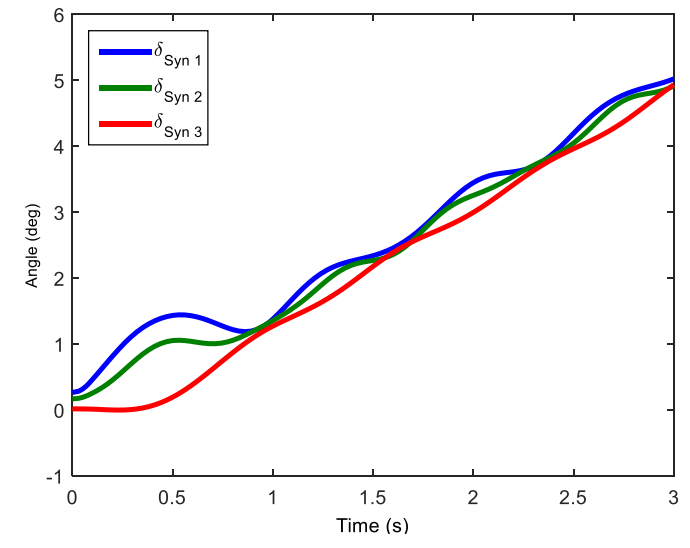

Figure 17. Rotor angle of three generators with wind power injection

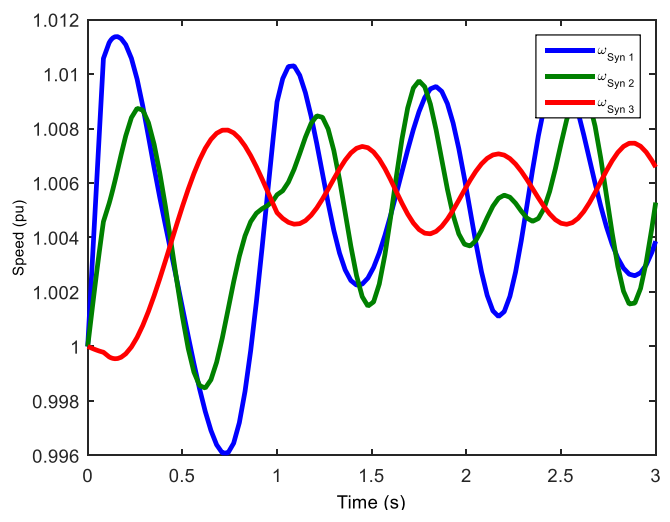

Figure 18. Speed of three generators with wind power injection

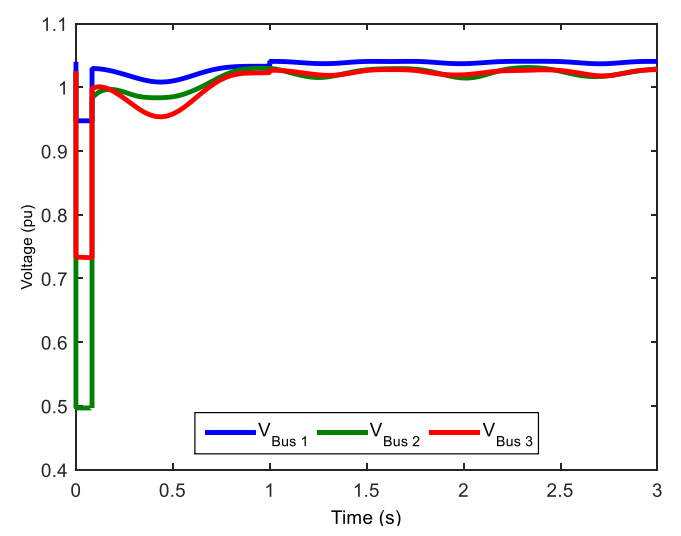

Figure 19. Voltage profile of bus connected of three generators with wind power injection

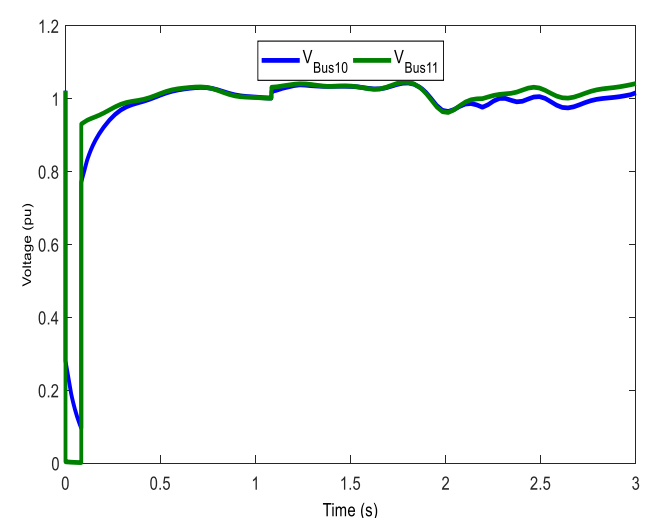

Figure 20. Voltage profile of wind farm bus connection with wind power injection

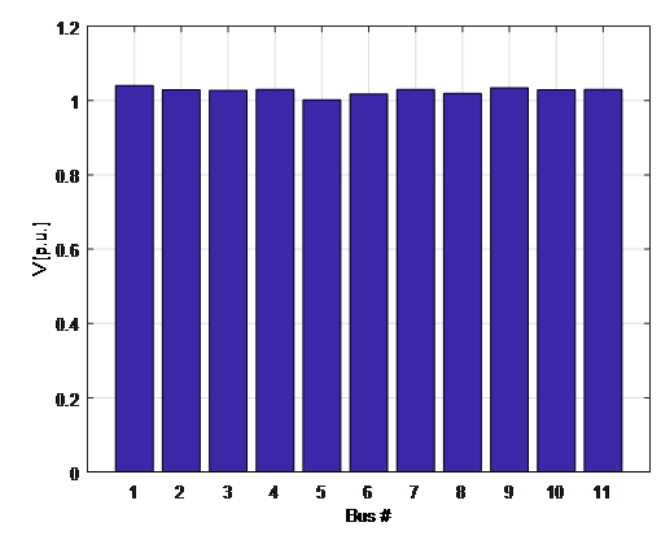

Figure 21. Specters of voltage of all bus with wind power injection

\section{CONCLUSIONS}

In this paper, instantaneous power control strategy for voltage improvement in power networks using wind turbine improving the dynamical response of power systems performances (voltage and transient stability) after fault has been proposed. The efficiency of proposed control has been tested using IEEE 9 Bus power system.

The advanced control strategies of wind generation system have been presented, suggested and developed. The generator side converter is controlled by sliding mode control (SMC) method. A control algorithm is to maximize the conversion of wind energy (MPPT) and an aerodynamic control serves to the security of wind turbine based on a Pitch Control. The results show that the control objectives are accomplished controls the variable speed wind turbine efficiently, with of steady state and transient conditions. The unity power factor operation is successfully achieved and there is no cross-coupling effect between active and reactive power.

These results demonstrate that the proposed controller confirms better disturbance rejection, keeps the control quality in the wider operating range, confirm the superiority of these control strategies that provide a precise instantaneous powers control and damps the power system oscillations.

\section{REFERENCES}

[1] Pinson, P., Chevallier, C., Kariniotakis, G.N. (2007). Trading wind generation from short-term probabilistic forecasts of wind power. In IEEE Transactions on Power Systems, 22(3):

$1148-1156$ http://dx.doi.org/10.1109/TPWRS.2007.901117

[2] Anderson, P.M., Fouad, A.A. (2003). Power System Control and Stability. Piscataway, N.J.: WileyInterscience.

[3] Domínguez-García, J.L., Gomis-Bellmunt, O., Bianchi, F.D., Sumper, A. (2012). Power oscillation damping supported by wind power: A review. Renewable and Sustainable Energy Reviews, 16(7): 4994-5006. http://dx.doi.org/10.1016/j.rser.2012.03.063

[4] Mahmud, N., Zahedi, A. (2016). Review of control strategies for voltage regulation of the smart distribution network with high penetration of renewable distributed generation. Renew. Sustainable Energy Rev., 64: 582595. http://dx.doi.org/10.1016/j.rser.2016.06.030

[5] Wu, Y.K., Han, G.Y., Lee, C.Y. (2013). Planning ten onshore wind farms with corresponding interconnection 
network and power system analysis for low-carbonisland development on Penghu Island, Taiwan. Renewable Sustainable Energy Rev., 19: 531-540. https://doi.org/10.1016/j.rser.2012.10.043

[6] Dai, M., Marwali, M.N., Jung, J., Keyhani, A. (2008). A three-phase four-wire inverter control technique for a single distributed generation unit in island mode. IEEE Trans. Power Electron., 23(1): 322-331. https://doi.org/10.1109/TPEL.2007.911816

[7] Kroposki, B., Pink, C., Basso, T., DeBlasio, R. (2007). Microgrid standards and technology development. IEEE Power Engineering Society General Meeting, Tampa, FL, pp. 1-4. https://doi.org/10.1109/PES.2007.1709139

[8] Malmedal, A., Kroposki, B., Sen, P. (2007). Energy policy act of 2005 and its impact on renewable energy applications in USA. IEEE Power Engineering Society General Meeting, Tampa, FL, pp. 1-4. https://doi.org/10.1109/PES.2007.386300

[9] Saoudi, K., Harmas, M.N. (2014). Enhanced design of an indirect adaptive fuzzy sliding mode power system stabilizer for multi-machine power systems. Electrical Power and Energy Systems, 54: 425-431. https://doi.org/10.1016/j.ijepes.2013.07.034

[10] Wang, C., Nehrir, M.H. (2007). Fuel cells and load transients. IEEE Power Energy Mag., 5(1): 58-63. https://doi.org/10.1109/MPAE.2007.264852

[11] Hernandez-Gonz'alez, G., Iravani, R. (2006). Current injection for active islanding detection of electronicallyinterfaced distributed resources. IEEE Trans. Power Delivery, 21(3): 1698-1705. https://doi.org/10.1109/TPWRD.2006.876980

[12] Kroposki, B., Levene, J., Harrison, K., Sen, P., Novachek, F. (2006). Electrolysis: opportunities for electric power utilities in a hydrogen economy. 2006 38th North American Power Symposium, Carbondale, IL, 2006, pp. 567-576. https://doi.org/10.1109/NAPS.2006.359628

[13] Kroposki, B., Pink, C., DeBlasio, R., Thomas, H., Simoes, M., Sen, P. (2006). Benefits of power electronic interfaces for distributed energy applications. IEEE Power Engineering Society General Meeting, Montreal, pp. 295-305. https://doi.org/10.1109/PES.2006.1709502

[14] Kroposki, B., Basso, T., DeBlasio, R., Friedman, N.R. (2006). Interconnection of alternative energy sources with the grid. in Invited Chapter in Integration of Alternative Sources of Energy, F. Farret and M. Simoes, editors, John Wiley \& Sons, Hoboken, NJ, 2006, pp. 295305.

[15] Menicucci, D., Ducey, R., Volkman, P. (2006). Energy Surety for Mission Readiness. Public Works Digest of the U.S. Army Installation Management Agency, vol. XVIII, no. 2, A publication of the U.S. Army Installation Management Agency, March/April 2006.

[16] Balog, R.S. (2006). Autonomous local control in distributed DC power systems. Ph.D. dissertation, University of Illinois at Urbana-Champaign, 2006.

[17] Wang, C., Nehrir, M.H., Gao, H. (2006). Control of PEM fuel cell distributed generation systems. IEEE Trans. Energy Conversion, 21(2): 586-595. https://doi.org/10.1109/TEC.2005.860404

[18] Jemei, S., Hissel, D., Coince, A., Al-Nasrawi, B. (2006). Optimization and economic analysis of a hybrid fuel cell, photovoltaic and battery electric power generation system. J. Fuel Cell Sci. Technol., 3(4): 410-414. https://doi.org/10.1115/1.2349521

[19] Abdallah, T., Ducey, R., Balog, R.S., Feickert, C., Weaver, W., Akhil, A., Menicucci, D. (2006). Control Dynamics of Adaptive and Scalable Power and Energy Systems for Military Microgrids. U.S. Army Engineer Research and Development Center, 2006.

[20] Gursoy, E., Niebur, D. (2006). On-line estimation of electric power system active loads neural networks. International Joint Conference on Neural Networks, pp. 1689-1694. https://doi.org/10.1109/IJCNN.2006.246638

[21] Menicucci, D., Ducey, R., Volkman, P. (2006). Energy surety for mission readiness. Public Works Digest of the U.S. Army Installation Management Agency. 18(2).

[22] Kundur, P. (1994). Power System Stability and Control. New York: McGraw Hill.

[23] Huda, A.S.N., Živanović, R. (2017). Large-scale integration of distributed generation into distribution networks: Study objectives, review of models and computational tools. Renewable Sustainable Energy, 76: 974-988. https://doi.org/10.1016/j.rser.2017.03.069

\section{NOMENCLATURE}

\begin{tabular}{|c|c|}
\hline$H_{i}$ & Inertia constant of SG \\
\hline$D_{i}$ & Damping constant of SG \\
\hline$\omega_{i}$ & Rotor angular velocity \\
\hline$\delta_{i}$ & Rotor angle \\
\hline$P_{m i}$ & $\begin{array}{l}\text { Mechanical input power of the i-th } \\
\text { generator }\end{array}$ \\
\hline$P_{e i}$ & Electrical input power of the i-th generator \\
\hline$\omega_{b}$ & Rotating angular velocity \\
\hline$T_{d 0 i}^{\prime}, T_{q 0 i}^{\prime}$ & $\mathrm{d}$-axis and q-axis transient time constants \\
\hline$E_{d i}^{\prime}, E_{q i}^{\prime}$ & $\mathrm{d}$-axis and q-axis transient emf \\
\hline$x_{d i}^{\prime}, x_{q i}^{\prime}$ & $\mathrm{d}$-axis and q-axis transient reactances \\
\hline$I_{d 0 i}^{\prime}, I_{q 0 i}^{\prime}$ & $\mathrm{d}$-axis and q-axis of the generator currents \\
\hline$V_{e x}$ & Field voltage controlled \\
\hline $\mathrm{Vt}$ & Terminal generator voltage \\
\hline $\mathrm{R}$ & Blade radius \\
\hline$V_{w}$ & Wind stream of velocity \\
\hline$\rho$ & Air density \\
\hline$C_{p}$ & Power coefficient of the wind turbine \\
\hline$n$ & Number of wind turbine \\
\hline$R_{r}, L_{r}$ & Line inductance and resistance \\
\hline$I_{r d}, I_{r q}$ & Grid currents in $(d, q)$ in reference frame \\
\hline$\omega_{g}$ & Angular frequency of grid voltage \\
\hline$V_{r d}, V_{r q}$ & $\begin{array}{l}\text { Control law design in }(d, q) \text { reference } \\
\text { frame }\end{array}$ \\
\hline$V_{r q}^{e q}, V_{r d}^{e q}$ & Equivalent control \\
\hline$P_{s_{-} r e f}, P_{s}$ & $\begin{array}{l}\text { Instantaneous estimated and set value of } \\
\text { active power }\end{array}$ \\
\hline$Q_{s_{-} r e f}, Q_{s}$ & $\begin{array}{l}\text { Instantaneous estimated and set value of } \\
\text { reactive power }\end{array}$ \\
\hline$s(P), s(Q)$ & Sliding surfaces \\
\hline$K_{V r q}, K_{V r d}$ & Positive constant \\
\hline
\end{tabular}

